\title{
Economic efficiency of radiology wards using data envelopment analysis: Case study of Iran
}

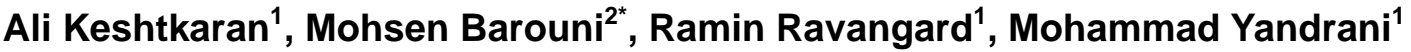 \\ ${ }^{1}$ Schools of Management and Medical Information Sciences, Shiraz University of Medical Sciences, Shiraz, Iran \\ ${ }^{2}$ Research Center for Health Services Management, Institute for Futures Studies in Health, Kerman University of Medical Sciences, \\ Kerman, Iran; ${ }^{*}$ Corresponding Author: mohsenbarooni@gmail.com
}

Received 28 November 2013; revised 31 December 2013; accepted 9 January 2014

Copyright (c) 2014 Ali Keshtkaran et al. This is an open access article distributed under the Creative Commons Attribution License, which permits unrestricted use, distribution, and reproduction in any medium, provided the original work is properly cited. In accordance of the Creative Commons Attribution License all Copyrights (c) 2014 are reserved for SCIRP and the owner of the intellectual property Ali Keshtkaran et al. All Copyright (C 2014 are guarded by law and by SCIRP as a guardian.

\section{ABSTRACT}

Background: In evaluating the activities and performance of radiology units, the main aim of applying feasible scientific methods is to use technological and human resources optimally. One of the suitable scientific methods in this field is determining the technical, economic, and allocative efficacy of these centers. We aimed to assess the economic efficiency of radiology units of hospitals affiliated to Shiraz University of Medical Sciences, southern Iran. Methods: In this descriptive-analytical cross-sectional study, the technical, economical, and allocative efficiency of 27 radiology units of public hospitals was assessed using data envelopment analysis. The input oriented envelopment form with the assumption of the varied outputs with respect to the scale was used. Related forms were filled using the existing information in the archives of radiology centers. Input variables in this study were the number of radiology devices, the number of expert personnel, the number of technicians, equipment maintenance and depreciation costs, and the salaries of the experts and technician. Output variables included the number of admitted patients and the number of photographic film. Then, data were analyzed using the DEAP software for calculating the various forms of efficiency. Results: The mean scores of economic, technical, and allocative efficiencies of radiology units were $0.749,0.880$, and 0.852 , respectively. The final score of economical efficiency was lower than the technical and allocative efficiency scores. Only $15 \%$ of radiology units were economically efficient. Conclusion: Economical efficiency can be attained when resources are used in the best possible way and not wasted. Therefore, a combination of inputs that comprise the lowest costs should be selected.

\section{KEYWORDS}

Economic Efficiency; Allocative Efficiency; Technical Efficiency; Data Envelopment Analysis; Radiology Wards

\section{INTRODUCTION}

Efficiency has been widely studied in scientific literature. This term is used anywhere where an activity is taking place. One of the reasons for the popularity of this concept is its importance in the society. The main issue regarding efficiency and its influencing factors is focused on how an activity can be efficient with lower costs and facilities, uses existing resources better, and prevents the waste of material and human resources [1].

In a broader spectrum, it can be hoped that the society will reach the required state of equilibrium and dynamic, so that each person's need would be met sufficiently and social organizations would become aware of their responsibilities and become efficient. Also, at the micro level, it could be hoped that an organization would use its resources and facilities correctly and attain specified goals. This process could be generalized to the personal level as well. A society, association, or organization needs capable, proud, and satisfied individuals who can perform their tasks efficiently in order to be able to achieve organizational goals. Therefore, the subject of efficiency is highly important in both micro and macro levels [2]. 
Economic efficiency is a unit's capability to achieve the maximum productivity and efficiency possible considering the costs and input levels to find the ratio between the least possible cost and the existing cost. Economic efficiency is obtained by multiplying technical and allocative efficiencies [3]. Therefore, in order to enhance economic efficiency, technical and allocative efficiencies should also be enhanced. Lack of economic efficiency is rooted in technical and allocative efficiencies and the lack of allocative efficiency is related to unsuitable distribution of interventions and different treatment methods, and incorrect use of different technologies. The lack of technical efficiency is related to waste of resources and financial assets including wrong and inferior equipment purchases or excess labor work [4].

Therefore, a health system has economic efficiency when it could present correct and adequate services (allocative efficiency) in a useful and proportionate manner (technical efficiency) [5]. Since paying attention to healthcare and investment in this field can increase the efficiency of the work force and productivity, allocating adequate resources and the optimal use of the resources is important in this regard [2]. Recent advances in knowledge, technology, healthcare, and treatment methods as well as the created changes in people's lifestyles and cultural and social structures, change in disease models and people's medical needs and the rapid population growth have complicated the supply of healthcare facilities and services. On the other hand, the optimal utilization of human and material resources for effective production and supply depends on awareness about economic regulations [6]. Advances in economic efficiency enable the healthcare system to perform better using existing resources and create justice and equality [4].

We aimed to assess the economic efficiency of radiology units of hospitals affiliated to Shiraz University of Medical Sciences, southern Iran using data envelopment analysis.

\section{MATERIALS AND METHODS}

This descriptive-analytical cross-sectional study was done during 2011 to assess the economic efficiency of 27 radiology units of hospitals affiliated to Shiraz University of Medical Sciences using data envelopment analysis. This method of analysis is one of the non-parametric methods of estimating functions as well as a linear programming technique. Sampling was not done since a limited number of university-affiliated public hospitals existed. This study is also an applicable study since hospital managers, other hospitals, and policy makers could benefit from the findings of the study.

Data were collected using simultaneous field and library studies using a researcher-designed checklist. In this checklist a list of needed data including the study inputs and outputs were recorded. Collected data were comparatively analyzed and assessed using the DEAP software. Analytic tests were done using SPSS software.

We studied the economic, allocative, technical, scale and management efficiencies of the radiology units using the data envelopment analysis assuming varied outputs with respect to the scale in an input-oriented fashion. The data used in our study were related to input variables such as imaging device, maintenance cost per year (considering device depreciation), number of expert personnel, number of technicians, and the salaries of experts and technicians. The output variables included number of admissions and number of $\mathrm{X}$-ray per year.

The important point to consider is that since different devices were used in the radiology units of different hospitals with different life spans (some less that and some more that 10 years), we used the direct methods for calculating device depreciation using scientific accounting literature and with the consultation of experts in accounting and economics. In the direct linear method a fixed percentage of initial assets are depreciated in the useful life of assets. However, the main point is that based on the textbooks and expert consultation, the maintenance cost was calculated for devices that were old according to available records [7]. This cost was quite considerable in existing contracts and affected the economic efficiency score. The maintenance and depreciation costs were calculated for devices that were less than 10 years old [8].

\section{RESULTS}

The results of the first stage of the study included The scale and management efficiencies of radiology units considering the type of their scale are shown in Table 1.

As shown in Table 1, the management and scale efficiencies of radiology units are very different from each other with scale and management efficiencies ranging from $0.201-1$ and $0.556-1$, respectively. Radiology units that performed efficiently with respect to both management and scale efficiencies during the study period were related to hospitals $3,13,15,16$, and 24 . These five radiology units had a fixed output with respect to scale that confirms their efficiency. Other units had an increasing output to scale which signals that they were not performing efficiently and for having scale efficiency they should increase their production capacity. The least scale (0.201) and management (0.556) efficiencies were related to the radiology units of hospitals 1 and 27, respectively.

Of the 27 units, 12 units had management efficiency as compared with 5 units with scale efficiency showing that they are less efficient in scale. Considering the ob- 
Table 1. Scale and management efficiency scores of radiology units of University-affiliated hospitals.

\begin{tabular}{cccccccc}
\hline Unit & Scale efficiency & Management efficiency & Type of output to scale & Unit & Scale efficiency & Management efficiency & Type of output to scale \\
\hline 1 & $0 / 201$ & 1 & Increasing & 15 & 1 & 1 & Fixed \\
2 & $/ 650$ & 1 & Increasing & 16 & 1 & 1 & Fixed \\
3 & 1 & 1 & Fixed & 17 & $/ 357$ & $0 / 918$ & Increasing \\
4 & $/ 574$ & 1 & Increasing & 18 & 1787 & 1 & Increasing \\
5 & $/ 559$ & $0 / 911$ & Increasing & 19 & $329 /$ & 1 & Increasing \\
6 & $/ 655$ & $0 / 920$ & Fixed & 20 & $0 / 929$ & $0 / 747$ & Increasing \\
7 & $/ 923$ & $0 / 9$ & Increasing & 21 & $0 / 596$ & $0 / 714$ & Increasing \\
8 & $/ 789$ & $0 / 609$ & Increasing & 22 & $0 / 7$ & $0 / 750$ & Increasing \\
9 & $/ 488$ & $0 / 672$ & Increasing & 23 & $0 / 755$ & $0 / 612$ & Increasing \\
10 & $/ 3$ & 1 & Increasing & 24 & 1 & 1 & Fixed \\
11 & $/ 234$ & $0 / 9$ & Increasing & 25 & $0 / 941$ & $0 / 763$ & Increasing \\
12 & $/ 858$ & $0 / 806$ & Increasing & 26 & $0 / 977$ & $0 / 992$ & Increasing \\
13 & 1 & 1 & Fixed & 27 & $0 / 769$ & 5 & Increasing \\
14 & $/ 301$ & 1 & Increasing & & & & \\
\hline
\end{tabular}

tained results the mean scale and management efficiencies of the studied radiology units during 2011 were 0.692 and 0.880 , respectively.

In the DEA methodology, formally developed by Charles, Cooper and Rhodes (1978), efficiency is defined as a ratio of weighted sum of outputs to a weighted sum of inputs, where the weights structure is calculated by means of mathematical programming and constant returns to scale (CRS) are assumed. In 1984, Banker, Charnes and Cooper developed a model with variable returns to scale (VRS).

In this table we report two types of efficiency (scale and management efficiency). If we divide constant return to scale efficiency (CRS) score to variable return to scale (VRS) efficiency (managerial) achieved scale efficiency. Constant return to scale efficiency not included in Table 1.

The results of the second stage of the study are the economic, allocative, and technical efficiencies of each radiology unit were calculated by considering costs.

According to Table 2, the mean economic efficiency of radiology units was 0.749 . This amount of efficiency shows that if these units were completely efficient they could reduce about $30 \%$ of their expenses and gain the same amount of output. The mean technical and allocative efficiencies were 0.880 and 0.852 , respectively. Table 3 shows the excess inputs calculated by estimating technical efficiency.

Table 3 shows the excess application of inputs using the non-parametric method assuming a varied output with respect to scale for radiology units. In other words this table shows how much each radiology unit should reduce its unit's input to reach technical efficiency.

Table 4 shows the optimum input amounts of radiology units at University-affiliated hospitals. This table is different from Table 3 because it shows the optimum economical amounts of the inputs for increasing economic efficiency, while Table 4 is after optimizing inputs for increasing the technical efficiency of radiology units.

In this study, a hypothesis was made about the mean economic efficiency of radiology units of Shiraz compared with other cities. We found that the mean economic efficiency of radiology units in Shiraz did not have a significant difference from other cities $(\mathrm{P}=$ 0.952).

\section{DISCUSSION}

Considering that hospitals play a crucial role in presenting healthcare services and can affect the efficiency of the whole healthcare system, applying the data envelopment method can enhance the performance of hospitals throughout the country.

We found that the mean scale efficiency scores of radiology units were 0.691 in 2011. Ferrier and colleague estimated the scale efficiency of 360 American hospitals to be 0.893 [9]. Other studies have stated a scale efficiency of 0.940 for 123 hospitals and about $0.790-1$ for 41 hospitals of the same country, respectively [10,11]. The scale efficiency of 55 hospitals in America was further reported to be 0.51 to 1 [12]. These estimations are consistent with our study.

In a study on 18 general hospitals in Iran, the researchers concluded that with respect to scale efficiency, Iranian hospitals had input (constant bed) problems. 14\% of hospital beds were inactive and this could indicate poor scale efficiency and indifference towards the use of financial resources [13]. In our study, the mean scale efficiency was similar to the latter study; although compared with other types of efficiency $18 \%$ of radiology units obtained complete scores. 
Table 2. Score and grade of economic, allocative, and technical efficiencies of radiology units during 2011.

\begin{tabular}{cccccccc}
\hline Unit & Technical efficiency & Allocative efficiency & Economic efficiency & Unit & Technical efficiency & Allocative efficiency & Economic efficiency \\
\hline 1 & 1 & $0 / 627$ & $0 / 627$ & 15 & 1 & 1 & 1 \\
2 & 1 & $0 / 608$ & $0 / 608$ & 16 & 1 & $0 / 704$ & $0 / 704$ \\
3 & 1 & 1 & 1 & 17 & $0 / 918$ & $0 / 861$ & $0 / 791$ \\
4 & 1 & $0 / 953$ & $0 / 953$ & 18 & 1 & $0 / 830$ & $0 / 830$ \\
5 & $0 / 911$ & $0 / 933$ & $0 / 850$ & 19 & 1 & $0 / 812$ & $0 / 812$ \\
6 & $0 / 920$ & $0 / 938$ & $0 / 862$ & 20 & $0 / 747$ & $0 / 705$ & $0 / 727$ \\
7 & $0 / 900$ & $0 / 903$ & $0 / 813$ & 21 & $0 / 714$ & $0 / 903$ & $0 / 644$ \\
8 & $0 / 609$ & $0 / 839$ & $0 / 511$ & 22 & $0 / 750$ & $0 / 699$ & $0 / 524$ \\
9 & $0 / 672$ & $0 / 978$ & $0 / 657$ & 23 & $0 / 612$ & $0 / 945$ & $0 / 578$ \\
10 & 1 & $0 / 977$ & $0 / 977$ & 24 & 1 & 1 & $0 / 672$ \\
11 & $0 / 900$ & $0 / 783$ & $0 / 705$ & 25 & $0 / 763$ & $0 / 781$ & $0 / 513$ \\
12 & $0 / 806$ & $0 / 925$ & $0 / 746$ & 26 & $0 / 992$ & $0 / 755$ \\
13 & 1 & 1 & 1 & 27 & $0 / 556$ & $0 / 887$ & $0 / 494$ \\
14 & 1 & $0 / 732$ & $0 / 732$ & Mean & $0 / 44$ & $0 / 814815$ & $0 / 72963$ \\
\hline
\end{tabular}

Table 3. Percentage of excess inputs with respect to input variables and radiology units.

\begin{tabular}{cccccccccc}
\hline Unit & $\begin{array}{c}\text { Economic } \\
\text { efficiency score }\end{array}$ & $\begin{array}{c}\text { Technical } \\
\text { efficiency }\end{array}$ & $\begin{array}{c}\text { Allocative } \\
\text { efficiency }\end{array}$ & $\begin{array}{c}\text { Economic } \\
\text { efficiency }\end{array}$ & Unit & $\begin{array}{c}\text { Economic } \\
\text { efficiency score }\end{array}$ & $\begin{array}{c}\text { Technical } \\
\text { efficiency }\end{array}$ & $\begin{array}{c}\text { Allocative } \\
\text { efficiency }\end{array}$ & $\begin{array}{c}\text { Economic } \\
\text { efficiency }\end{array}$ \\
\hline 1 & 17 & 1 & $0 / 627$ & $0 / 627$ & 15 & 1 & 1 & 1 & 1 \\
2 & 18 & 1 & $0 / 608$ & $0 / 608$ & 16 & 14 & 1 & $0 / 704$ & $0 / 704$ \\
3 & 1 & 1 & 1 & 1 & 17 & 9 & $0 / 918$ & $0 / 861$ & $0 / 791$ \\
4 & 3 & 1 & $0 / 953$ & $0 / 953$ & 18 & 6 & 1 & $0 / 830$ & $0 / 830$ \\
5 & 5 & $0 / 911$ & $0 / 933$ & $0 / 850$ & 19 & 8 & 1 & $0 / 812$ & $0 / 812$ \\
6 & 4 & $0 / 920$ & $0 / 938$ & $0 / 862$ & 20 & 20 & $0 / 747$ & $0 / 705$ & $0 / 727$ \\
7 & 7 & $0 / 900$ & $0 / 903$ & $0 / 813$ & 21 & 16 & $0 / 714$ & $0 / 903$ & $0 / 644$ \\
8 & 22 & $0 / 609$ & $0 / 839$ & $0 / 511$ & 22 & 21 & $0 / 750$ & $0 / 699$ & $0 / 524$ \\
9 & 15 & $0 / 672$ & $0 / 978$ & $0 / 657$ & 23 & 19 & $0 / 612$ & $0 / 945$ & $0 / 578$ \\
10 & 2 & 1 & $0 / 977$ & $0 / 977$ & 24 & 1 & 1 & 1 & 1 \\
11 & 13 & $0 / 900$ & $0 / 783$ & $0 / 705$ & 25 & 20 & $0 / 763$ & $0 / 672$ & $0 / 513$ \\
12 & 11 & $0 / 806$ & $0 / 925$ & $0 / 746$ & 26 & 10 & $0 / 992$ & $0 / 781$ & $0 / 755$ \\
13 & 1 & 1 & 1 & 1 & 27 & 23 & $0 / 556$ & $0 / 887$ & $0 / 494$ \\
14 & 12 & 1 & $0 / 732$ & $0 / 732$ & & & & & \\
\hline
\end{tabular}

Table 4. The optimum economic amount of inputs in order to minimize the costs of radiology units.

\begin{tabular}{|c|c|c|c|c|c|c|c|}
\hline Unit & First input (expert) & $\begin{array}{l}\text { Second input } \\
\text { (Technician) }\end{array}$ & $\begin{array}{c}\text { Third input } \\
\text { (Imaging device) }\end{array}$ & Unit & First input (Expert) & $\begin{array}{l}\text { Second input } \\
\text { (Technician) }\end{array}$ & $\begin{array}{c}\text { Third input } \\
\text { (Imaging device) }\end{array}$ \\
\hline 1 & 0 & 3 & 2 & 15 & 6 & 4 & 6 \\
\hline 2 & 0 & 3 & 2 & 16 & 2 & 2 & 2 \\
\hline 3 & 1 & 4 & 2 & 17 & 0 & 3 & 2 \\
\hline 4 & 13 & 3 & 2 & 18 & 16 & 4 & 3 \\
\hline 5 & $/ 2$ & 3 & $2 / 7$ & 19 & 0 & 3 & 2 \\
\hline 6 & $/ 8$ & 3 & 2 & 20 & 4 & 5 & 4 \\
\hline 7 & 2 & 6 & 4 & 21 & 1 & 3 & 2 \\
\hline 8 & 1 & $4 / 5$ & $2 / 5$ & 22 & $/ 6$ & 4 & 3 \\
\hline 9 & $/ 3$ & 3 & 2 & 23 & 1 & 4 & 2 \\
\hline 10 & 0 & 3 & 2 & 24 & 31 & 10 & 14 \\
\hline 11 & 0 & 3 & 2 & 25 & 7 & 5 & $6 / 5$ \\
\hline 12 & $1 / 5$ & $4 / 5$ & 3 & 26 & 3 & 6 & 5 \\
\hline 13 & 3 & 7 & 6 & 27 & 1 & 5 & 2 \\
\hline 14 & 0 & 3 & 2 & & & & \\
\hline
\end{tabular}


It should be noted that pure technical efficiency (management efficiency) is possible only if technical efficiency is estimated under fixed output conditions with respect to the scale. Moreover, most studies around the globe have focused on technical and scale efficiencies rather than management efficiency. Our findings on evaluating management efficiencies showed a score of 0.2 to 1 . The mean management efficiency, assuming a fixed output to scale (0.605) was less than scale efficiency and management efficiency assuming a varied output to scale. Pure technical efficiency is an indicator of correct management and a correct combination of production frontiers. During 2011, about 19\% of studied hospitals were completely efficient in this regard. In a previous study on 10 public hospitals in Tehran, Iran, the mean management efficiency score during an 8-year period was estimated to be 0.963 (range: 0.788 - 1) [3].

In our study, considering the mean technical efficiency score $(0.880)$, there is a $12 \%$ potential for improving the efficiency of radiology units. Also, this shows that $45 \%$ of radiology units had a technical efficiency score of 1 and were efficient. Moreover, units that did not have complete efficiency had excess production factors, especially expert personnel (39\%). This is consistent with another similar study reporting an excess input related to paramedical personnel (38.54\%).

Allocative efficiency is obtained by dividing economic efficiency and technical efficiency assuming a varied output with respect to scale. In fact, after determining the price on inputs in the model, allocative efficiency becomes important. Lack of allocative efficiency is related to the inadequate distribution of resources (between interventions and different treatment methods) and the incorrect use of various technologies. About $15 \%$ of radiology units have complete allocative efficiency. The allocative efficiency scores of the 27 studies units was in a logical range $(0.6-1)$. In this study the mean allocative efficiency (0.852) was less than the mean technical efficiency $(0.880)$. Allocative efficiency of private and public Iranian hospitals was respectively 0.76 and 0.77 in a previous report [14].

The economic efficiency of radiology units is obtained by multiplying technical and allocative efficiencies. Economic efficiency is reached is resources are not wasted and used optimally. This in turn depends on selecting a combination of inputs with the least costs. In this study, we evaluated the different types of efficiencies of radiology units of public hospitals. The mean economic efficiency score of these units was 0.749 which was lower than their allocative and technical efficiencies. Of course, the obtained number was the result of multiplying technical and allocative efficiencies. The least obtained economic efficiency score was that of hospital 27 (0.495).
This lack of efficiency is mostly related to technical efficiency than allocative efficiency. The highest economic efficiency score was related to hospitals 3, 13, 15, and 24 with a score of 1 . These hospitals were completely efficient with respect to their technical and allocative efficiencies. In other words, about $15 \%$ of radiology units were economically efficient. In a study on 94 public hospitals in Spain, an economic efficiency of $24.5 \%$ was reported. In a study among 21 public hospitals in Fars province the mean economic efficiency score was reported to be 0.53 [4]. Moreover, Sheikhzadeh and colleagues reported mean economic efficiency scores of 0.52 and 0.68 for private and public hospitals, respectively [14].

This study is the only study done on the economic efficiency of radiology units using the data envelopment analysis method. Most studies in this regard have focused on technical efficiency. Moreover, we included all public hospitals affiliated to Shiraz University of Medical Sciences. We also performed a systematic study on the input and output variables with respect to previous studies considering the importance of their correct selection. On the other hand, our study also had some limitations. In Iran, in all efficiency evaluations, the inputs and outputs are similarly weighted. For example, when the number of experts, technicians, physicians, and active beds are considered as inputs in an efficiency study, a similar impact or weigh is considered for a technician and a physician. This could be considered as a weakness per se. The DEAP2 software cannot distinguish the weight of the variables. This problem is also evident in the outputs. For instance, when the number of healthy discharged patients is considered as an output, all patients that are discharged from various wards are considered equal. In reality, a patient that is discharged from the orthopedics ward is not in the same condition as a patient discharged from the surgery wards.

\section{CONCLUSION}

Economical efficiency can be attained when resources are used in the best possible way and not wasted. Therefore, a combination of inputs that comprise the lowest costs should be selected.

\section{ACKNOWLEDGEMENTS}

We would like to thank all the personnel of the studied hospitals.

\section{AUTHORS' CONTRIBUTION}

All authors contributed equally.

\section{FUNDING/SUPPORT}

This study has been derived from the thesis of the last author with a 
grant from the Vice-Chancellor of Research Affairs of Shiraz Univer-sity of Medical Sciences (grant number: 6360).

\section{REFERENCES}

[1] Saber Mahani, A., et al. (2012) Comparing the efficiency of kerman province towns in acquiring human development index via data envelopment analysis. Iranian Red Crescent Medical Journal, 14, 248-249.

[2] Despotis, D.K. (2005) A reassessment of the human development index via data envelopment analysis. Operational Research Society Journal, 56, 969-80.

[3] Cooper, W.W., Seiford, L.M. and Tone, K. (2007) Data Envelopment Analysis: A comprehensive text with models, applications, references and DEA-solver software. Springer Science and Business Media, LLC, New York.

[4] Nahid, H., et al. (2012) Cost efficiency of the family physician plan in Fars Province, Southern Iran. Iranian Journal of Medical Sciences, 37, 253-259.

[5] Giokas, D. (2002) The use of goal programming, regression analysis and data envelopment analysis for estimating efficient marginal cost of hospital services. Multicriteria Decision Analysis, 11, 261-268.

[6] Newbrander, W., Barnum, H. and Kutzin, J. (1992) Hospital economics and financing in developing countries, WHO.

[7] Somanathan, A., Honson, K. and Doralawila, T. (2000) Operating efficiency in public sector health facilities in sirilanka: Measurement and institutional determinantes of performance. PHR.

[8] Ferrier, G.D. and Lovell, C.A.K. (1990) Measuring cost efficiency in banking econometrics and linear programming evidence. Journal of Econometrics, 46, 229-245. http://dx.doi.org/10.1016/0304-4076(90)90057-Z

[9] Byrnes, P. (1994) Analysing technical and allocative efficiency of hospitals. In: Charnes, A., Cooper, W. and Lewin, A., Eds., DEA Theory, Methodology and Applications, Kluwer, Boston.

[10] Valdmanis, V. (1992) Sensivity Analysis for DEA Model -An empirical example using public vs. NFP hospital. Journal of Public Economics, 48, 185-205.

[11] Maindiratta, A. (1990) Largest size-efficient scale and size efficiencies of decision-making units in data envelopment analysis. Journal of Econometrics, 46, 57-72. http://dx.doi.org/10.1016/0304-4076(90)90047-W

[12] Hatam, N. (2008) The role of data envelopment analysis (DEA) pattern in the efficiency of social security hospitals in Iran. Iranian Red Crescent Journal, 10, 2-7.

[13] Sheikhzadeh, Y., Roudsari, A.V., Vahidi, R.G., Emrouznejad, A. and Dastgiri, S. (2012) Public and private hospital services reform using data envelopment analysis to measure technical, scale, allocative, and cost efficiencies. Health Promotion Perspectives, 2, 28-41.

[14] Pouing, C.J. and Liu, J.T. (1994) Estimation of non-neutral stochastic frontier production function. Journal of Productivity Analysis, 5, 171-180. 